\title{
Retraction Note to: Single volar locking plating for the intra- and extra-articular distal radius fractures with dorsal metaphyseal comminution
}

\author{
Xue-yang Gui ${ }^{1 \dagger}$, Zhao-hui Cheng ${ }^{2 \dagger}$, Hong-fei Shi $^{2 *}$, Yi-xin Chen $^{1}$, Jin Xiong ${ }^{1}$, Jun-fei Wang ${ }^{1}$, Xu-sheng Qiu ${ }^{1}$ and \\ Zi-tao Zhang ${ }^{1}$
}

\section{Retraction Note to: Journal of Orthopaedic Surgery and Research (2021) 16:530}

https://doi.org/10.1186/s13018-021-02641-w

The authors have retracted this article because after publication it was noted that data from a previous version of the study had been mistakenly included in multiple sections of this article. The authors, therefore, no longer have confidence in the validity of the results. All authors agree to this retraction.
Published online: 09 February 2022

\section{Publisher's Note}

Springer Nature remains neutral with regard to jurisdictional claims in published maps and institutional affiliations.

\section{Author details}

'Department of Orthopedics, Nanjing Drum Tower Hospital, The Affiliated Hospital of Nanjing University Medical School, No. 321 Zhongshan Road, Nanjing, China. ${ }^{2}$ Nanjing Drum Tower Hospital Clinical College of Nanjing Medical University, Nanjing, China.

*Correspondence: michaelshi@nju.edu.cn

${ }^{\dagger}$ Xue-yang Gui and Zhao-hui Cheng contributed equally to this work

${ }^{2}$ Nanjing Drum Tower Hospital Clinical College of Nanjing Medical University, Nanjing, China

Full list of author information is available at the end of the article to the material. If material is not included in the article's Creative Commons licence and your intended use is not permitted by statutory regulation or exceeds the permitted use, you will need to obtain permission directly from the copyright holder. To view a copy of this licence, visit http://creativecommons.org/licenses/by/4.0/. The Creative Commons Public Domain Dedication waiver (http://creativeco mmons.org/publicdomain/zero/1.0/) applies to the data made available in this article, unless otherwise stated in a credit line to the data. 